\title{
Neuromuscular features in sprinters with cerebral palsy: case studies based on paralympic classification
}

\author{
Diego Antunes' ${ }^{1}$, Mateus Rossato ${ }^{1,2}$, Rafael Lima Kons ${ }^{1, *}$, Raphael Luiz Sakugawa', Gabriela Fischer ${ }^{1}$ \\ 'Biomechanics Laboratory, Federal University of Santa Catarina, Florianópolis, Brazil \\ ${ }^{2}$ Human Performance Laboratory, Federal University of Amazonas, Manaus, Brazil
}

Despite the evolution of runner performance in athletes with cerebral palsy (CP), little is known about neuromuscular parameters of sprinters from different classes, especially related to power output, muscular imbalances and asymmetry indexes in lower limbs. The aim of this study was to assess muscle power, muscular imbalance and asymmetry in sprinters with CP. Four male sprinters with CP (age, 18 to 27 years; body mass, 58.5 to $72.8 \mathrm{~kg}$; height, 161.5 to $174 \mathrm{~cm}$ ) classified as T38, T37, T36, T35 according to International Paralympic Committee functional classification, performed vertical counter movement jump and squat jump on force plate and isokinetic torque evaluations in both limbs. The concentric peak torque (PT) was measured at $60 \% \mathrm{sec}, 120 \% \mathrm{sec}$ and $180 \% \mathrm{sec}$ and PT eccentric at $60 \% \mathrm{sec}$ and $120 \% \mathrm{sec}$. The asymmetry indexes, conventional and functional ratios were assessed. the results showed that athletes with more severe impairments (T35 and T36) showed worse performance to muscle power, more muscular imbalance and higher asymmetry in PT between limbs (>10\%). The exception was T37 athlete, who presented the better performance for all variables. it is concluded that CP athletes with more severe impairments showed lower jumping performance and torque production of knee extensors and flexors, they showed greater asymmetries between limbs. Finally, considering the results of T37 athlete, it seems that the athletic training for a longer period can reverse part of the neuromuscular impairments caused by CP.

Keywords: Paralympic sports, Sports biomechanics, Isokinetic evaluation, Cerebral palsy

\section{INTRODUCTION}

Cerebral palsy (CP) is defined as a nonprogressive disease that affects the development of the central nervous system, compromising the coordination of movements and posture (Sankar and Mundkur, 2005). Its prevalence around the world is 2-3.5 per 1,000 live-births (Colver et al., 2014) and the risk factors are multifactorial occurring in either prenatal, natal or postnatal care. CP is most typically associated with limitations in gross motor functioning, muscle spasticity, and cognitive impairment (Mukherjee and Gaebler-Spira, 2007). Consequently, this population has a reduction in quality of life, especially due to physical activity limitation (Rimmer et al., 2004; Ryan et al., 2017).

Sports participation is a good alternative to improve the physical and psychosocial functioning of individuals with CP (Carroll

et al., 2006; Ross et al., 2016). In the Paralympic Sports program, athletes with $\mathrm{CP}$ are eligible to participate in several sports, being athletics (track and field) one of them. In the attempt to minimize the impact of their impairment on the outcome of competition (Tweedy and Vanlandewijck, 2011), the athletes with CP are divided into different functional sports classes: T35 (moderate diplegia and triplegia); T36 (dystonia, athetosis or ataxia); T37 (hemiplegia); and T38 (mild hypertonia, ataxia, or athetosis) (International Paralympic Committee, 2017).

Despite the evolution of runner performance in athletes with $\mathrm{CP}$, little is known about neuromuscular parameters of sprinters from different classes, especially related to power output, muscular imbalances and asymmetry indexes in lower limbs. Recently, Runciman et al. (2016), verified that athletes with hemiplegia (T37 and T38) showed lower jump height with two legs in comparison with

${ }^{*}$ Corresponding author: Rafael Lima Kons (B) https://orcid.org/0000-0003-1615-5464 Federal University of Santa Catarina, Center of Sports, Biomechanics Laboratory, Florianópolis, Santa Catarina 88040-900, Brazil Tel \& Fax: +55-48-3721-8530, E-mail: rafakons0310@gmail.com Received: September 6, 2017 / Accepted: December 9, 2017 tribution Non-Commercial License (http://creativecommons.org/licenses/by-nc/4.0/) which permits unrestricted non-commercial use, distribution, and reproduction in any medium, provided the original work is properly cited. 
able-bodied. On the contrary, when compared nonaffected limbs, the jump height (unilateral jump) was similar between groups. In addition, the authors observed similarity in the magnitude of fatigue between athletes with $\mathrm{CP}$ and able-bodied post multistage shuttle run test. This behavior was observed in another study (Runciman et al., 2016) as well. Runciman et al. (2016), attribute the similarity in fatigue to the high-level training over many years of elite athletes with CP. However, these studies did not discuss differences between the studied functional sport classes.

Regarding isokinetic parameters, to the best of our knowledge, only one study assessed muscular imbalances and asymmetries in soccer players with CP (Andrade et al., 2005). The results revealed asymmetry between limbs affected and nonaffected and higher prevalence of muscular imbalance in $\mathrm{CP}$ group. Nevertheless, these findings are not enough to understand how much different levels of movement/posture disorders could affect neuromuscular parameters in $\mathrm{CP}$ athletes and consequently sport performance. Even the relationship between muscular strength and running performance remains unclear in this population. According to Beckman et al. (2016), strength could be a limiting factor for running performance, mainly for those $\mathrm{CP}$ athletes with more severe impairments.

In able-bodied sprinters, the imbalance among agonist/antagonist muscles has been associated with greater hamstring injury potential (Babu et al., 2016). We believe that references values to muscular imbalances and asymmetries for this population could give some directions to injury prevention and training strategies. Therefore, the aim of this study was to assess the parameters of power, muscular imbalance and asymmetry indexes in sprinters with $\mathrm{CP}$ from different functional sports classes. It was hypothesized that, the worse the neuromuscular parameters will be, greater the impairment of functional class.

\section{MATERIALS AND METHODS}

\section{Participants}

Participated in this study 4 athletes with CP specialists in sprint events (Table 1). They trained regularly at least 3 times per week for at least $2 \mathrm{hr}$ a day. The study conformed to the standards set by the Declaration of Helsinki and was approved by the Institutional Human Research Ethics Committee of the local University. The individual anthropometric characteristic, International Paralympic Committee classification, level of competition, $\mathrm{CP}$ characteristics and best time to complete 100-m race are showed in Table 1.

\section{Experimental design}

Before assessed power and torque of lower limbs, anthropometric variables as height, body mass, and skin fold thicknesses were collected and the fat percentage was calculated based on Siri equation. Then, the athletes performed vertical counter movement jump (CMJ), squat jump (SJ), and isokinetic torque evaluations in both limbs. The concentric peak torque (PT) were measured at $60 \%$ sec, $120 \%$ sec, and $180 \%$ sec and PT eccentric at $60 \%$ sec and $120 \%$ sec. The conventional $(60 \% \mathrm{sec}, 120 \% \mathrm{sec}$, and $180 \% \mathrm{sec})$ and functional ratios $(60 \% \mathrm{sec}$ and $120 \% \mathrm{sec})$ were assessed. Asymmetry indexes for PT of knee extensors and flexors were also assessed for concentric contractions $\left(60^{\circ} / \mathrm{sec}, 120 \% \mathrm{sec}\right.$, and $\left.180^{\circ} / \mathrm{sec}\right)$ and eccentric $(60 \% \mathrm{sec}$ and $120 \% \mathrm{sec})$ contractions for both limbs. The main outcomes were jump height, peak power, PT, muscular ratios and asymmetry index.

\section{Power of lower limbs}

The analysis of muscular power of lower limbs were evaluated on force plate (Quattro Jump, model 9290AD, Kistler, Winterthur, Switzerland) during the CMJ and SJ. The frequency of acquisition was $500 \mathrm{~Hz}$. CMJ: the athlete started at a static standing position with hands on the hip, and the jump was preceded by a countermovement of acceleration below the center of gravity achieved by flexing their knees to about $90^{\circ}$, an angle that was observed and visually controlled by the examiner. During the jump, the trunk was kept as vertical as possible, and the athlete was instructed to jump at the highest possible speed and to the highest point that they could reach. SJ: the athlete started the jump from a static position, with the knees at an angle of about $90^{\circ}$, the trunk

Table 1. Cerebral palsy athlete's characteristics

\begin{tabular}{|c|c|c|c|c|c|c|c|c|c|c|}
\hline Athlete & $\begin{array}{l}\text { Age } \\
\text { (yr) }\end{array}$ & $\begin{array}{l}\text { Height } \\
(\mathrm{cm})\end{array}$ & $\begin{array}{l}\text { Body mass } \\
(\mathrm{kg})\end{array}$ & $\begin{array}{c}\text { Body fat } \\
(\%)\end{array}$ & $\begin{array}{l}\text { Level of com- } \\
\text { petition }\end{array}$ & Impairment & $\begin{array}{c}\text { Spasticity } \\
\text { grades }\end{array}$ & $\begin{array}{l}\text { Affected } \\
\text { side }\end{array}$ & $\begin{array}{c}\text { Experience } \\
\text { (yr) }\end{array}$ & $\begin{array}{c}100-\mathrm{m} \\
(\mathrm{sec})\end{array}$ \\
\hline T38 & 21 & 169 & 69.79 & 18.7 & Regional & Mild hypertonia & 0 & Left & 1 & $17 " 00$ \\
\hline T37 & 27 & 174 & 72.80 & 10.5 & International & Spastic hemiplegia & $3-2$ & Right & 8 & $12 " 05$ \\
\hline T36 & 25 & 161.5 & 58.5 & 10.8 & National & Ataxia/athetosis & 0 & Both & 1 & $15 " 40$ \\
\hline T35 & 18 & 171 & 61 & 10.8 & National & Spastic triplegia & $3-2$ & Both & 3 & $19 " 32$ \\
\hline
\end{tabular}


as vertical as possible, and the hands on the waist. The jump was performed without any countermovement, and there was only the concentric action of the agonist muscles involved in the movement.

Before the vertical jump assessment, the participants performed a familiarization/warm-up period involving $30 \mathrm{sec}$ of hopping on a trampoline, three series of 10 hops on the ground, and five submaximal countermovement vertical jumps, after familiarization athletes performed 3 attempts for $\mathrm{CMJ}$ and 3 attempts for $\mathrm{SJ}$. The parameters were obtained as follows: (a) Jump height: calculated using the ground reaction force (GRF) double integration method, (b) peak power: greater value of the curve obtained from the multiplication of the GRF by the velocity in the concentric phase of the jump, normalized by the body mass. The stretch shortening cycle (SSC) performance gain as a percentage was calculated using the below equation: SSC performance $(\%)=([\mathrm{CMJ}-\mathrm{SJ}] / \mathrm{SJ}) \times 100$ (Walshe et al., 1996).

\section{Torque measure}

All participants performed a familiarization and a warm-up protocol (20 knee flexion-extension concentric submaximal repetitions at $120 \%$ sec) using an isokinetic dynamometer (Biodex System 4 Pro, Biodex Medical Systems, Shirley, NY, USA). The participants were positioned as the manufacturer's recommendations for evaluation of knee flexion-extension movements. Firstly, was evaluated right knee posteriorly the left knee. The same protocol was used in both limbs. After the warm-up, subjects performed 2 attempts of 5 contractions in mode concentric/concentric for quadriceps and hamstrings). In sequence, the subjects performed 2 attempts of 5 contractions in mode eccentric reactive (eccentric for hamstrings and eccentric for quadriceps muscles). For concentric contractions were used the $60 \% \mathrm{sec}, 120 \% \mathrm{sec}$, and $180 \% \mathrm{sec}$, and for eccentric contraction were used only $60^{\circ} / \mathrm{sec}$ and $120^{\circ} / \mathrm{sec}$. The range of motion was $70^{\circ}\left(30^{\circ}\right.$ to $100^{\circ}$, considering $0^{\circ}=$ total knee extension) and 2-min rest period was respect between trials. The highest PT value obtained among the three attempts was considered the maximal torque eccentric and concentric respectively. Torque data were sampled at $100 \mathrm{~Hz}$ and smoothed using fifth-order,

Table 2. Individual neuromuscular parameters assessed in CMJ and SJ

\begin{tabular}{lccllll}
\hline & \multicolumn{2}{c}{ CMJ } & & \multicolumn{2}{c}{ SJ } & \\
\cline { 2 - 3 } Athlete & $\begin{array}{c}\text { Jump height } \\
(\mathrm{cm})\end{array}$ & $\begin{array}{c}\text { Peak power } \\
(\mathrm{w} / \mathrm{kg})\end{array}$ & & $\begin{array}{c}\text { Jump height } \\
(\mathrm{cm})\end{array}$ & $\begin{array}{c}\text { Peak power } \\
(\mathrm{w} / \mathrm{kg})\end{array}$ & $\begin{array}{c}\text { SSC } \\
(\%)\end{array}$ \\
\hline T38 & $28.6 \pm 0.3$ & $33.0 \pm 2.0$ & & $27.2 \pm 0.5$ & $34.2 \pm 1.0$ & 5.15 \\
T37 & $46.1 \pm 1.0$ & $49.2 \pm 1.3$ & & $42.6 \pm 1.1$ & $45.7 \pm 0.4$ & 8.21 \\
T36 & $21.2 \pm 0.7$ & $32.9 \pm 1.6$ & & $18.8 \pm 1.1$ & $32.3 \pm 1.3$ & 12.92 \\
T35 & $18.7 \pm 0.7$ & $32.7 \pm 0.8$ & & $17.2 \pm 0.3$ & $30.1 \pm 0.8$ & 8.51 \\
\hline
\end{tabular}

Values are presented as mean \pm standard deviation. CMJ, counter movement jump; SJ, squat jump.

Table 3. Individual peak torque (PT) for right and left extensors/flexors of knee during concentric and eccentric contraction in different angular velocity

\begin{tabular}{|c|c|c|c|c|c|c|c|}
\hline \multirow{3}{*}{$\begin{array}{l}\text { Athlete } \\
\text { T38 }\end{array}$} & \multirow{2}{*}{\multicolumn{2}{|c|}{ Side/muscle group }} & \multicolumn{2}{|c|}{$60^{\circ} / \mathrm{sec}$ (N.m) } & \multicolumn{2}{|c|}{$120^{\circ} / \mathrm{sec}$ (N.m) } & \multirow{2}{*}{$\begin{array}{c}180^{\circ} / \mathrm{sec} \text { (N.m) } \\
\text { PTConc }\end{array}$} \\
\hline & & & \multirow{2}{*}{$\begin{array}{c}\text { PTConc } \\
251\end{array}$} & \multirow{2}{*}{$\begin{array}{c}\text { PTExc } \\
367\end{array}$} & \multirow{2}{*}{$\begin{array}{c}\text { PTConc } \\
185\end{array}$} & \multirow{2}{*}{$\begin{array}{c}\text { PTExc } \\
307\end{array}$} & \\
\hline & Right & Quadriceps & & & & & 141 \\
\hline & & Hamstrings & 179 & 191 & 159 & 163 & 81 \\
\hline & Left* & Quadriceps & 190 & 244 & 155 & 189 & 119 \\
\hline & & Hamstrings & 150 & 177 & 151 & 170 & 66 \\
\hline \multirow[t]{4}{*}{ T37 } & Right* & Quadriceps & 342 & 376 & 296 & 387 & 230 \\
\hline & & Hamstrings & 199 & 200 & 203 & 209 & 106 \\
\hline & Left & Quadriceps & 342 & 425 & 310 & 417 & 204 \\
\hline & & Hamstrings & 212 & 220 & 203 & 207 & 137 \\
\hline \multirow[t]{4}{*}{ T36 } & Right* & Quadriceps & 182 & 198 & 123 & 111 & 114 \\
\hline & & Hamstrings & 123 & 126 & 72 & 62 & 72 \\
\hline & Left ${ }^{*}$ & Quadriceps & 179 & 139 & 128 & 184 & 104 \\
\hline & & Hamstrings & 59 & 81 & 59 & 75 & 47 \\
\hline \multirow[t]{4}{*}{ T35 } & Right* & Quadriceps & 66 & 118 & 67 & 68 & 49 \\
\hline & & Hamstrings & 62 & 114 & 69 & 131 & 21 \\
\hline & Left ${ }^{*}$ & Quadriceps & 114 & 112 & 77 & 87 & 77 \\
\hline & & Hamstrings & 83 & 134 & 55 & 65 & 39 \\
\hline
\end{tabular}

PTConc, peak torque concentric; PTExc, peak torque eccentric; N.m, Newton per meter.

${ }^{*}$ Affected limb. 
zero-phase, and recursive low-pass Butterworth filter with a cutoff frequency of $10 \mathrm{~Hz}$ and normalized by body mass. The conventional ratio was calculated by concentric PT of hamstrings $\left(\mathrm{H}_{\text {con }}\right)$ : concentric PT of quadriceps $\left(\mathrm{Q}_{\mathrm{con}}\right)$ and functional ratio by eccentric PT hamstrings $\left(\mathrm{H}_{\text {ecc }}\right.$ ): concentric PT of quadriceps $\left(\mathrm{Q}_{\mathrm{con}}\right)$ (Aagaard et al., 1998). The data are presented as the mean \pm standard deviation.

\section{RESULTS}

The individual values of CMJ, SJ, and SSC are showed in Table 2. All parameters to $\mathrm{CMJ}$ and $\mathrm{SJ}$ were lower for athletes with more severe impairment. The exception was T37 athlete, who showed the higher level of training and the better time to $100 \mathrm{~m}$. Besides, T36 athlete had the best use of the SSC.

PT values were lower to T38 athlete's left limb (affected) for all angular velocities. Differently, T37 athlete (right limb affected), showed lower PT in $60 \%$ sec and $120^{\circ} / \mathrm{sec}$ in eccentric contraction and $120 \%$ sec in concentric contraction and higher in $180 \%$ sec concentric contraction. T36 and T35 athletes showed lower PT values in all angular velocities (Table 3).

When analyzed the ratios, the results showed that the hamstrings in general are the weakened muscle (Table 4). The functional ratio (hamstrings eccentric: quadriceps concentric) is more affected (60\% sec and $180^{\circ} / \mathrm{sec}$ ) (values $<1$ ). The functional ratio, by involving eccentric contractions of hamstrings, requires greater degree of coordination and showed that this muscular group produces lower PT eccentrically in both angular velocities evaluated. The conventional ratio analysis showed that higher velocity $\left(180^{\circ} / \mathrm{sec}\right)$ seems

Table 4. Individual conventional ratio $\left(\mathrm{H}_{\text {con }}: \mathrm{Q}_{\text {con }}\right)$ for $60^{\circ} / \mathrm{sec}, 120^{\circ} / \mathrm{sec}$, and $180 \%$ sec and functional ratio $\left(H_{\text {ecc }}: \mathrm{O}_{\text {con }}\right)$ for $60 \%$ sec and $120 \%$ sec

\begin{tabular}{|c|c|c|c|c|c|c|}
\hline \multirow[t]{2}{*}{ Athlete } & \multirow[t]{2}{*}{ Limb } & \multicolumn{2}{|c|}{$\begin{array}{c}60^{\circ} / \mathrm{sec} \\
\text { (N.m) }\end{array}$} & \multicolumn{2}{|c|}{$\begin{array}{c}120^{\circ} / \mathrm{sec} \\
\text { (N.m) }\end{array}$} & \multirow{2}{*}{$\begin{array}{c}180^{\circ} / \mathrm{sec} \\
\text { (N.m) } \\
\text { Conv. ratio }\end{array}$} \\
\hline & & Conv. ratio & Func. ratio & Conv. ratio & Func. ratio & \\
\hline \multirow[t]{2}{*}{ T38 } & Right & 0.71 & 0.76 & 0.86 & 0.88 & 0.57 \\
\hline & Left $^{*}$ & 0.79 & 0.93 & 0.97 & 1.10 & 0.55 \\
\hline \multirow[t]{2}{*}{ T37 } & Right* & 0.58 & 0.58 & 0.69 & 0.71 & 0.46 \\
\hline & Left & 0.62 & 0.64 & 0.65 & 0.67 & 0.67 \\
\hline \multirow[t]{2}{*}{ T36 } & Right* & 0.71 & 0.69 & 0.59 & 0.50 & 0.63 \\
\hline & Left $^{*}$ & 0.33 & 0.45 & 0.46 & 0.59 & 0.45 \\
\hline \multirow[t]{2}{*}{ T35 } & Right* & 0.94 & 1.73 & 1.03 & 1.96 & 0.43 \\
\hline & Left $^{*}$ & 0.73 & 1.18 & 0.71 & 0.84 & 0.51 \\
\hline
\end{tabular}

$\mathrm{H}_{\mathrm{ecc}}$, eccentric peak torque hamstrings; $\mathrm{Q}_{\mathrm{con}}$, concentric peak torque of quadriceps; Conv., conventional; Func., functional.

${ }^{*}$ Affected limb. to be most affected (values $<0.60$ ), likely due to high degree of muscular coordination involvement.

The athletes with hypertonia and spastic hemiplegia in one limb (T38 and T37 athletes) showed lower asymmetry index in all contraction form and angular velocities. The T37 athlete showed to be more symmetrical. On the other hand, T36 and T35 athletes presented the highest asymmetry indexes, possibly because they have more severe impairments (Table 5).

\section{DISCUSSION}

The purpose of this study was to assess the muscle power, muscular imbalance and asymmetry in sprint runners with CP from different sport classes. The main results indicate that the athletes with more severe impairments T35 and T36 showed worse performance in muscle power, more muscular imbalance and higher asymmetry in PT between limbs. The exception was T37 athlete, who showed the best performance, which was contrary to our hypothesis. We believe that despite being an intermediate class, the high level of training of T37 athlete could explain his best performance and better neuromuscular features. This finding helps to sustain that an evidence-based classification process is crucial, because an effect of training could mask the true athlete's sport class.

Our study showed that athlete T36 has better use (12.6\%) of SSC in relation to the other athletes (T35, 8.51\%; T37, 8.21\%; T38, 5.15\%). This finding could be explained by the fact that athlete T36 does not have spasticity. According to Lieber et al. (2004) the alterations that occur in spastic muscle (hypertonia) interfered in the better use of SSC. Considering vertical jumps, T35 and $\mathrm{T} 36$ athletes presented smallest performance values. These athletes had the both legs affected, different from T37 and T38

Table 5. Individual values of asymmetry index (\%) between lower limbs

\begin{tabular}{|c|c|c|c|c|c|c|}
\hline \multirow[t]{2}{*}{ Athlete } & \multirow{2}{*}{$\begin{array}{l}\text { Muscle } \\
\text { group }\end{array}$} & \multicolumn{2}{|c|}{$\begin{array}{l}60^{\circ} / \mathrm{sec} \\
\text { (N.m) }\end{array}$} & \multicolumn{2}{|c|}{$\begin{array}{c}120^{\circ} / \mathrm{sec} \\
\text { (N.m) }\end{array}$} & \multirow{2}{*}{$\begin{array}{c}180^{\circ} / \mathrm{sec} \\
\text { (N.m) } \\
\text { PTConc }\end{array}$} \\
\hline & & PTConc & PTExc & PTConc & PTExc & \\
\hline \multirow[t]{2}{*}{ T38 } & Quadriceps & 13.8 & 20.1 & 8.8 & 23.8 & 8.5 \\
\hline & Hamstrings & 8.8 & 3.8 & 2.6 & 2.1 & 10.2 \\
\hline \multirow[t]{2}{*}{ T37 } & Quadriceps & 0.0 & 6.1 & 2.3 & 3.7 & 6.0 \\
\hline & Hamstrings & 3.2 & 4.8 & 0.0 & 0.5 & 12.8 \\
\hline \multirow[t]{2}{*}{ T36 } & Quadriceps & 0.8 & 17.5 & 2.0 & 24.7 & 4.6 \\
\hline & Hamstrings & 35.2 & 21.7 & 9.9 & 9.5 & 21.0 \\
\hline \multirow[t]{2}{*}{ Т35 } & Quadriceps & 26.7 & 2.6 & 6.9 & 12.3 & 22.2 \\
\hline & Hamstrings & 14.5 & 8.1 & 11.3 & 33.7 & 30.0 \\
\hline
\end{tabular}

PTConc, peak torque concentric; PTExc, peak torque eccentric; N.m, Newton per meter. 
athletes who have on limb affected. The values found to CMJ (T35$19 \mathrm{~cm}$, T36-21 cm, T37-46 cm, T38-29 cm and to SJ (T35-17 $\mathrm{cm}, \mathrm{T} 36-19 \mathrm{~cm}, \mathrm{~T} 37-43 \mathrm{~cm}, \mathrm{~T} 38-29 \mathrm{~cm}$ ) in our study are much lower when compared with sprinters without CP (CMJ, $54.72 \pm$ $5.46 \mathrm{~cm}$; SJ, $51.93 \pm 4.81 \mathrm{~cm}$ ) (Dal Pupo et al., 2012). Similarly, Yanci et al. (2016), found values to CMJ $(24 \mathrm{~cm})$ and $S J(20 \mathrm{~cm})$ of football players with CP largely lower than that reported for players without $\mathrm{CP}$.

Our findings are the first involving evaluation of isokinetic PT in sprinters with $\mathrm{CP}$ from different functional sports classes at different velocities. Considering PT values between limbs, we observed greater differences in T37 e T38 because they present only one limb affected. T35 e T36 showed lower PT values because the both limbs were affected. This lower performance in affected limb could be associated with central deficits include impaired central drive resulting in lower voluntary muscle activation and impaired motor unit firing rate modulation with altered firing sequencing, which could manifest as spasticity and coactivation (Moreau et al., 2009; Stackhouse et al., 2005). Beckman et al. (2017), state that strength levels are determinant for running activities among people with brain impairment, and their evaluation is encouraged as a functional classification criterion. Indeed, De Groot et al. (2012), reported moderate correlation $\left(R^{2}=0.34\right)$ between the PT $\left(60^{\circ}\right)$ sec) and sprint power evaluated by means of the Wingate test. In agreement, the weaker athlete (T35) and the stronger athlete (T37) in our study showed the worst and best time to $100 \mathrm{~m}$, respectively.

The evaluation of muscle ratios in able-bodied sprinters is important to identify muscle imbalances and possible future injuries (Yeung et al., 2009). Such imbalances are generally related to shorter optimum angle for PT (Brockett et al., 2004), muscle fatigue (Mair et al., 1996), inadequate warm-up (Safran et al., 1998), previous injury (Gabbe et al., 2006), age (Agre, 1985), and weakness of the hamstring muscles (Croisier et al., 2002). We did not find studies in the literature that had evaluated the muscle ratios at different speeds in sprinters with CP. Andrade et al. (2005), evaluated the PT of concentric contractions at $60 \%$ sec of soccer players with spastic hemiparesis and reported that $42 \%$ of the participants had the conventional ratio, at least of the one limb, out of normal range. Interestingly, the limb most affected by imbalances was the nonaffected by CP. The data of present study indicate a high incidence of muscular imbalances as well, both in the conventional ratio and in the functional ratio. T36 athlete showed the greatest number of imbalances. On the other hand, the T35 athlete, possibly due to the low PT values, had the lowest values of imbalances. Athletes with CP usually show high rates of asymmetry during running (Pope and Sherrill, 1993) but it is not clear its impact on performance. Exell et al. (2012), showed that asymmetry and running performance do not have a relationship in able-bodied athletes. This could be attributed to a lower asymmetric index $(<3.16 \%)$ that probably not alter the kinematic of running performance (Carpes et al., 2010). On the contrary, our data indicate that athletes who showed more severe impairments (T35 and T36) also present more asymmetric PT (>10\%) and a lower running performance. Our values are similar to those reported by Andrade et al. (2005), $23 \% \pm 13 \%$ between knee extensors and $24 \% \pm 12 \%$ for flexors in soccer players with CP. It is interesting to mention that the authors evaluated only the $60^{\circ}$ sec velocity. Further studies are necessary to investigate whether such high asymmetries values are associated with the incidence of injuries and running performance. The study has limitations to be addressed. Firstly, we evaluated only four athletes. This low sample did not allow to perform a robust statistical analysis and make generalizations. Anyway, we believe that these four-case studies provided a better understating about neuromuscular features in CP sprinters. Furthermore, four sprinters with CP from different adjacent classes are very difficult to group. Secondly, despite the time spend with familiarization, mild intellectual impairments may have interfered in tests performance.

We conclude that $\mathrm{CP}$ athletes with more severe impairments showed lower jumping performance and torque production of knee extensors and flexors. In addition, they showed greater asymmetries between limbs. Finally, considering the results of T37 athlete, it seems that the athletic training for a longer period can reverse part of the neuromuscular impairments caused by $\mathrm{CP}$.

\section{CONFLICT OF INTEREST}

No potential conflict of interest relevant to this article was reported.

\section{REFERENCES}

Aagaard P, Simonsen EB, Magnusson SP, Larsson B, Dyhre-Poulsen P. A new concept for isokinetic hamstring: quadriceps muscle strength ratio. Am J Sports Med 1998;26:231-237.

Agre JC. Hamstring injuries. Proposed aetiological factors, prevention, and treatment. Sports Med 1985;2:21-33.

Andrade MS, Fleury AM, da Silva AC. Isokinetic muscular strength of paralympic athletes with cerebral palsy $(\mathrm{CP})$ from the Brazilian soccer team. Rev Bras Med Esporte 2005;11:263e-266e. 
Babu AN, West A, Joyce A, Borg-Stein J. Hamstring injuries: review of current literature and return to play considerations. Curr Phys Med Rehabil Rep 2016;4:145-153.

Beckman EM, Connick MJ, Tweedy SM. Assessing muscle strength for the purpose of classification in Paralympic sport: A review and recommendations. J Sci Med Sport 2017;20:391-396.

Beckman EM, Connick MJ, Tweedy SM. How much does lower body strength impact Paralympic running performance? Eur J Sport Sci 2016;16:669-676

Brockett CL, Morgan DL, Proske U. Predicting hamstring strain injury in elite athletes. Med Sci Sports Exerc 2004;36:379-387.

Carpes FP, Mota CB, Faria IE. On the bilateral asymmetry during running and cycling: a review considering leg preference. Phys Ther Sport 2010; 11:136-142.

Carroll KL, Leiser J, Paisley TS. Cerebral palsy: physical activity and sport. Curr Sports Med Rep 2006;5:319-322.

Colver A, Fairhurst C, Pharoah PO. Cerebral palsy. Lancet 2014;383:12401249.

Croisier JL, Forthomme B, Namurois MH, Vanderthommen M, Crielaard JM. Hamstring muscle strain recurrence and strength performance disorders. Am J Sports Med 2002;30:199-203.

Dal Pupo J, Detanico D, dos Santos SG. Kinetic parameters as determinants of vertical jump performance. Rev Bras Cineantropom Desempenho Hum 2012;14:41-51.

De Groot S, Janssen TW, Evers M, Van der Luijt P, Nienhuys KN, Dallmeijer AJ. Feasibility and reliability of measuring strength, sprint power, and aerobic capacity in athletes and non-athletes with cerebral palsy. Dev Med Child Neurol 2012;54:647-653.

Exell TA, Gittoes MJ, Irwin G, Kerwin DG. Gait asymmetry: composite scores for mechanical analyses of sprint running. J Biomech 2012;45: 1108-1111.

Gabbe BJ, Bennell KL, Finch CF, Wajswelner H, Orchard JW. Predictors of hamstring injury at the elite level of Australian football. Scand J Med Sci Sports 2006;16:7-13.

International Paralympic Committee. World Para Athletics Classification Rules and Regulations. Bonn (Germany): International Paralympic Committee; 2017.

Lieber RL, Steinman S, Barash IA, Chambers H. Structural and functional changes in spastic skeletal muscle. Muscle Nerve 2004;29:615-627.

Mair SD, Seaber AV, Glisson RR, Garrett WE Jr. The role of fatigue in susceptibility to acute muscle strain injury. Am J Sports Med 1996;24:137143.
Moreau NG, Li L, Geaghan JP, Damiano DL. Contributors to fatigue resistance of the hamstrings and quadriceps in cerebral palsy. Clin Biomech (Bristol, Avon) 2009;24:355-360.

Mukherjee S, Gaebler-Spira DJ. Cerebral palsy. In: Braddom RL, editor. Physical medicine and rehabilitation. 3rd ed. Philadelphia: 2007. p. 1243-1268.

Pope C, Sherrill C, Wilkerson J, Pyfer J. Biomechanical variables in sprint running of athletes with cerebral palsy. Adapt Phys Act Q 1993;10:226255.

Rimmer JH, Riley B, Wang E, Rauworth A, Jurkowski J. Physical activity participation among persons with disabilities: barriers and facilitators. Am J Prev Med 2004;26:419-425.

Ross SM, MacDonald M, Bigouette JP. Effects of strength training on mobility in adults with cerebral palsy: A systematic review. Disabil Health J 2016;9:375-384.

Runciman P, Tucker R, Ferreira S, Albertus-Kajee Y, Derman W. Effects of induced volitional fatigue on sprint and jump performance in paralympic athletes with cerebral palsy. Am J Phys Med Rehabil 2016;95:277290.

Ryan JM, Cassidy EE, Noorduyn SG, O'Connell NE. Exercise interventions for cerebral palsy. Cochrane Database Syst Rev 2017;6:CD011660.

Safran MR, Garrett WE Jr, Seaber AV, Glisson RR, Ribbeck BM. The role of warmup in muscular injury prevention. Am J Sports Med 1988;16: 123-129.

Sankar C, Mundkur N. Cerebral palsy-definition, classification, etiology and early diagnosis. Indian J Pediatr 2005;72:865-868.

Stackhouse SK, Binder-Macleod SA, Lee SC. Voluntary muscle activation, contractile properties, and fatigability in children with and without cerebral palsy. Muscle Nerve 2005;31:594-601.

Tweedy SM, Vanlandewijck YC. International Paralympic Committee position stand: background and scientific principles of classification in Paralympic sport. Br J Sports Med 2011;45:259-269.

Walshe AD, Wilson GJ, Murphy AJ. The validity and reliability of a test of lower body musculotendinous stiffness. Eur J Appl Physiol Occup Physiol 1996;73:332-339.

Yanci J, Castagna C, Los Arcos A, Santalla A, Grande I, Figueroa J, Camara J. Muscle strength and anaerobic performance in football players with cerebral palsy. Disabil Health J 2016;9:313-319.

Yeung SS, Suen AM, Yeung EW. A prospective cohort study of hamstring injuries in competitive sprinters: preseason muscle imbalance as a possible risk factor. Br J Sports Med 2009;43:589-594. 